\title{
Política de formação de professores nas últimas décadas no Brasil: auanços, desafios, possibilidades e retrocessos
}

\author{
Teacher training policy in the last decades in Brazil: aduances, \\ challenges, possibilities and setbacks
}

\section{La política de formación de profesores en las últimas décadas en Brasil: auances, desafíos, posibilidades y retrocesos}

\author{
Breynner Ricardo Oliveira' \\ Universidade Federal de Ouro Preto, Departamento de Gestão Pública, Professor no \\ Programa de Pós-Graduação em Educação \\ Waleska Medeiros de Souza² \\ Prefeitura Municipal de Mariana, Minas Gerais, Professora \\ Leidelaine Sérgio Perucci ${ }^{3}$ \\ Universidade Federal de Ouro Preto, Graduanda em Pedagogia
}

Resumo: Neste artigo descrevem-se e analisam-se as principais políticas de formação de professores gestadas desde os anos 1990, concentrando-se nos Governos de Fernando Henrique Cardoso, Luís Inácio Lula da Sila, Dilma Rousseff e Michel Temer. $O$ percurso analítico empreendido revela que as ações de formação inicial e continuada de professores têm forte vinculação com a agenda governamental e que têm sido sistematicamente contingenciadas pelos ciclos político-eleitorais. Ao descrever e analisar as políticas e os programas desenhados nesses Governos percebe-se que a alternância da agenda é marcada pela questão orçamentária, especialmente nos Governos Dilma e Temer. A consequência é o desmantelamento da rede de formação que foi gestada no nível local e regional, ancorada pelas universidades, responsáveis pela articulação com os estados e municípios brasileiros.

Palavras-chave: Política educacional. Formação de professores. Conjuntura educacional.

\footnotetext{
Doutor e Mestre em Educação pela Universidade Federal de Minas Gerais.

Graduada em Pedagogia pela Universidade Federal de Ouro Preto.

Graduanda em Pedagogia na Universidade Federal de Ouro Preto.
} 
Abstract: This article describes and analyzes the main teacher training policies since the 1990s, focusing on the Governments of Fernando Henrique Cardoso, Luís Inácio Lula da Silva, Dilma Rousseff and Michel Temer. The analysis carried out reveals that initial and continuing teacher training actions are strongly linked to the government agenda and have been systematically constrained by political-electoral cycles. In describing and analyzing the policies and programs designed in these Governments it is clear that the alternation of the agenda is marked by the budget issue, especially in the Dilma and Temer Governments. The consequence is the dismantling of the training network that was created at the local and regional level, anchored by the universities, responsible for articulation with Brazilian states and municipalities.

Keywords: Educational policies. Teacher training. Educational scenario.

Resumen: Este artículo describe y analiza las principales políticas de formación de profesores gestadas desde los años 1990, concentrándose en los Gobiernos de Fernando Henrique Cardoso, Luis Inacio Lula da Sila, Dilma Rousseff y Michel Temer. El recorrido analítico emprendido revela que las acciones de formación inicial y continuada de profesores tienen fuerte vinculación con la agenda gubernamental y que han sido sistemáticamente contingenciadas por los ciclos políticos-electorales. Al describir y analizar las políticas y los programas diseñados en esos Gobiernos se percibe que la alternancia de la agenda está marcada por la cuestión presupuestaria, especialmente en los Gobiernos Dilma y Temer. La consecuencia es el desmantelamiento de la red de formación que fue gestada a nivel local y regional, anclada por las universidades, responsables de la articulación con los estados y municipios brasileños.

Palabras clave: Política educativa. Formación de profesores. Conyuntura y educación.

\section{INTRODUÇÃO}

Pretendeu-se, neste artigo, realizar uma discussão acerca da política de formação de professores no contexto político brasileiro das últimas décadas, mais especificamente dos últimos 25 anos, considerando as ações realizadas desde o Governo de Fernando Henrique Cardoso (FHC) até o Governo de 
Michel Temer. Tal percurso ressalta os avanços, os desafios, as possibilidades e os retrocessos que o campo tem experimentado.

Estado assegura a educação pública como direito social de todos na Constituição Federal de 1988 (CF/88), definindo que o poder público e a família têm o dever de promover e incentivar a educação com a colaboração da sociedade, "visando ao pleno desenvolvimento da pessoa, seu preparo para o exercício da cidadania e sua qualificação para o trabalho." (BRASIL, 1988). Na esteira da CF/88, é criada a Lei de Diretrizes e Bases para a Educação Nacional (LDB), Lei n. 9.394/1996. Com ela, emerge a ideia da criação de uma Base Nacional Curricular Comum (BNCC), que se consolida em 2017. em um governo marcado por uma brusca mudança no itinerário das políticas públicas, incluindo as educacionais.

Neste artigo descrevem-se e analisam-se as principais políticas de formação de professores gestadas desde os anos 1990. Na primeira seção, o Governo de Fernando Henrique é analisado a partir da Reforma do Estado, elemento que definiu as bases da política educacional no âmbito da Nova Gestão Pública, de cunho liberal. A seção seguinte trata da mudança de paradigma a partir dos governos de centro-esquerda, analisando os Governos Lula e Dilma. Na terceira, as ações nesse campo são analisadas no Governo de Michel Temer. Apesar de não haver evidências de que esse Governo tenha uma política consistente para a formação de professores, a seção é relevante porque destaca a retomada da agenda liberal no Brasil, ainda que de maneira precária.

Nesse sentido, percebe-se, nesse percurso, que as ações voltadas para a formação de professores no Brasil têm sido largamente contingenciadas pelo "zigue-zague" que tem prevalecido no Ministério da Educação (MEC), conforme descrito por Cunha (2006). Ainda que o autor tenha analisado os Governos FHC e Lula, suas percepções podem ser estendidas para os Governos Dilma e Temer, que, por razões distintas, promoveram alterações nos programas voltados para o campo da formação, comprometendo a rede de formação que se formou no nível local, ancorada nas universidades, responsáveis pela articulação com os estados e municípios. 


\section{A POLÍTICA DE FORMAÇÃO INICIAL E CONTINUADA DE PROFESSORES NO GOUERNO DE FHC: A AGENDA EDUCACIONAL NO CONTEXTO DE REFORMA DO ESTADO}

\subsection{O GOUERNO DE FHC (1994-2002)}

FHC $^{4}$ foi presidente do Brasil por dois mandatos consecutivos (19942002) e imprimiu em seu governo uma agenda de reformas com forte apelo liberal. Nesse período, diversos monopólios públicos foram desfeitos por meio de uma política ampla de privatizações, reorientando diversos setores estratégicos para o setor privado, ampliando a política de abertura das fronteiras para a universalização do capital, uma das exigências do mundo globalizado capitalista (SILVA JÚNIOR, 2002).

O Governo FHC foi marcado por diversas políticas no campo educacional, com destaque para a proposição de sólidos indicadores que medissem a qualidade do ensino, que até então o Brasil não possuía (SILVA JÚNIOR, 2002). A partir de 1995, o Sistema de Avaliação da Educação Básica $(\mathrm{SAEB})^{5}$ passa por regularização e é aperfeiçoado. Um dos resultados desse processo foi a inclusão do País na avaliação internacional feita pela Organização para a Cooperação e Desenvolvimento Económico (OCDE). A partir de então, o País passa a ter dados consistentes e reais de modo a fomentar o debate sobre a qualidade da educação e o desempenho escolar para, consequentemente, incidir nas políticas educacionais e aprimorar seus desenhos e estratégias de implementação e operacionalização, juntamente com os estados e os municípios.

Em que pesem os avanços provenientes de tal estruturação, questionase "[...] a forma autoritária e impositiva pela qual vêm sendo implementados e

\footnotetext{
4 Fernando Henrique Cardoso foi eleito Presidente com 54,2\% dos votos válidos, com uma chapa composta pelo seu partido, Partido da Social Democracia Brasileira (PSDB), e o Partido da Frente Liberal (PFL). Fez coalizões com as forças políticas conservadoras do País para enfrentar o candidato de esquerda Luiz Inácio Lula da Silva do Partido dos Trabalhadores (PT).

5 Sistema de Avaliação da Educação Básica (SAEB) é composto por um conjunto de avaliações externas em larga escala e possui como maior objetivo realizar um diagnóstico da educação básica brasileira, como a qualidade do ensino ofertado.
} 
sua eficácia quanto à melhoria e aperfeiçoamento das instituições." (SHIROMA; MORAES; EVANGELISTA, 2004, p. 96). Para Hypolito (2011), a ênfase nas avaliações externas tem forte vinculação com a Reforma liberal do Estado sob a influência da Nova Gestão Pública, quando a administração pública passa a adotar os cânones da gestão privada, orientando-se pelos princípios da eficiência, da meritocracia e dos resultados, alinhando-se com os interesses do mercado.

Nesse cenário liberal, as políticas de formação de professores no Brasil foram profundamente influenciadas pelas recomendações internacionais, com especial destaque para a conferência Mundial de Educação para Todos (UNESCO. 1990) realizada no ano 1990, em Jomtien. O Brasil foi um dos signatários desse documento que, dentre outras questões vinculadas ao campo da educação, trouxe à tona a questão da oferta de educação básica de qualidade. A Declaração Mundial sobre Educação para Todos é um dos "[...] marcos importantes na luta pela universalização da educação básica (de qualidade), compreendida como elemento central na conquista da cidadania." (UNESCO, 2001, p. 5). Com efeito, a educação básica deve passar a centrar "[...] na aquisição e nos resultados efetivos da aprendizagem, e não mais exclusivamente na matrícula, frequência aos programas estabelecidos e preenchimento dos requisitos para a obtenção do diploma." (UNESCO, 1990, p. 5).

Dentre esses organismos internacionais, destacamos como parte fundamental da contextura da retomada das políticas públicas educacionais a OCDE, o Banco Internacional para a Reconstrução e o Desenvolvimento (BIRD), o Fundo Monetário Internacional (FMI) e o Banco Mundial (BM), que, diretamente, têm influenciado as políticas educacionais por meio de recomendações e também de acordos bilaterais ou multilaterais (CROSSO; AZZI; BOCK, 2007). No Brasil, “[...] a influência do Banco Mundial tem um impacto significativo nas políticas educacionais, menos pelo investimento em projetos específicos e mais pela influência nas grandes orientações das políticas públicas." (CROSSO; AZZI; BOCK, 2007, p. 6). Em consonância, Soares (2003) afirma que o Banco Mundial "[... financiou um tipo de desenvolvimento econômico desigual e perverso socialmente, que ampliou a pobreza mundial, concentrou renda, aprofundou a exclusão e destruiu o meio ambiente." (SOARES, 2003, p. 17). 
Em 1996, após muitos embates políticos na Câmara dos Deputados e no Senado Federal, o projeto apresentado pelo Senador Darcy Ribeiro foi sancionado sem qualquer veto (SHIROMA; MORAIS; EVANGELISTA, 2004; SAVIANI, 1997) e em 20 de dezembro é promulgada a Lei de Diretrizes e Bases (LDB), mediante a Lei n. 9.394. Com a implementação da nova LDB, ocorreu uma nova configuração da relação entre o Governo, os Estados e os Municípios, impulsionada pela política liberal de descentralização das responsabilidades com a Educação. Dessa forma, cada ente federado passa a deter a obrigatoriedade de ofertar uma determinada modalidade de ensino conforme a LDB:

Art. 1 1, inciso V - o Município é incumbido de oferecer a educação infantil e com prioridade o ensino fundamental, Art. 10, inciso VI - os Estados devem ser responsáveis por assegurar o ensino fundamental e oferecer com prioridade o ensino médio e Art. 9०, inciso II a União deve manter os órgãos e instituições oficiais do sistema federal de ensino e ainda (Art. 9\%, inciso IV) tem encargo de articular toda a organização da educação nacional.

Nesse cenário, surgem ações para avaliar e definir os rumos das políticas educacionais. Dentre essas estratégias, destacam-se os mecanismos de financiamento e de avaliação com a elaboração de planos e ações nos níveis estadual e municipal, bem como a criação de avaliações externas para cumprir as recomendações internacionais (CATANI; OLIVEIRA, 2002). Outro aspecto da Lei de Diretrizes e Bases é a inclinação de sinais mercadológicos como balizadores do processo de reestruturação da educação superior, com uma nova percepção do trabalho acadêmico.

É nesse contexto político brasileiro que emergiram pesquisas de autores internacionais que inspiraram a nova concepção de formação inicial e continuada de professores do País: Nóvoa (1991) e o desenvolvimento profissional; Schön (1992, 1995) com o professor reflexivo e Zeichner (1998) com $\circ$ professor-pesquisador. Desde então, um amplo e intenso debate se estabeleceu em torno das percepções existentes sobre a formação inicial 
e continuada dos docentes, refletindo diretamente nas ações que seriam implementadas pelos governos subsequentes.

Por meio da Secretaria de Educação a Distância (SEED), o MEC desenvolveu alguns programas e projetos de formação adotando a educação a distância (EaD) como estratégia para alcançar um maior número de professores nas diversas regiões do País, incluindo as mais desiguais, remotas e com elevado número de professores em serviço sem titulação. $\bigcirc$ objetivo da SEED era pôr-se como mediadora na formação inicial e continuada dos professores, articulando e implementando o novo paradigma educacional conectado às mudanças em curso no âmbito político, econômico e social. A EaD passa a ser considerada uma modalidade de ensino, e, assim, ocorre sua institucionalização. Com efeito, surge o Programa de Formação de Professores em Exercício (Proformação), um curso de magistério de nível médio promovido pelo MEC em parceria com estados e municípios voltado para professores que ainda não tinham a formação específica (CUNHA, 2000):

Programa de Formação de Professores em Exercício (Proformação), desenvolvido sob os auspícios do Ministério da Educação (MEC) com o objetivo de oferecer diploma de ensino médio a professores leigos; organizado em módulos, com multimeios e currículo organizado em eixos articuladores, atendeu até 2006 em torno de cinquenta mil docentes nas regiões Centro-Oeste, Norte e Nordeste [...] (GATTI, 2008, p. 60).

Inicialmente, o Proformação ofertou vagas para as regiões Norte, Nordeste e Centro-Oeste. O projeto piloto do Programa foi implantado em 1999 , nos Estados do Mato Grosso e Mato Grosso do Sul. Nesse Programa inicial, foram habilitados 1.323 professores em julho de 2001. No plano estadual, dois programas de educação continuada se destacaram: o Programa de Capacitação de Professores (Procap) e o Programa de Educação Continuada (PEC) (GATTI, 2008, p. 58).

Procap foi formulado pela Secretaria Estadual de Educação de Minas Gerais em 1996. Ofertado na modalidade a distância, esse Programa tinha como público-alvo os professores de $1^{a}$ a $4^{a}$ séries das redes estaduais e 
municipais - as primeiras séries do ensino fundamental. $\bigcirc$ Programa objetivava capacitar mais de 80 mil docentes do primeiro ciclo, que ministravam os conteúdos de português, matemática, história, geografia e ciências (GATTI, 2008, p. 58).

$\bigcirc$ Estado de São Paulo também desenhou um programa próprio. PEC foi implementado nos anos 1996 a 1998, na modalidade presencial. Esse Programa visava à qualificação profissional dos professores. $\bigcirc$ destaque do Programa era sua política de abrangência, uma vez que contemplava, além dos professores do ensino fundamental ( $1^{a}$ a $8^{a}$ séries), também os diretores, os pedagogos e os dirigentes regionais (GATTI, 2008).

Mesmo consistindo em iniciativas isoladas dos governos de Minas Gerais e de São Paulo, essas ações apresentaram determinados pontos positivos em sua execução e vigência. O Procap trouxe como ponto positivo "[...] o compromisso das agências central e locais com a capacitação, o agendamento no calendário escolar de cada escola e a criação de incentivo para o professor participar." (GATTI, 2008, p. 59). Já o PEC se sobressaiu na "[...] tentativa de atendimento de necessidades locais, a inserção do professor como sujeito ativo no processo de capacitação e a utilização da metodologia da ação-reflexão nas capacitações." (GATTI, 2008, p. 59).

A gestão escolar foi contemplada com uma política pública particular oportunizada no desenho de um Programa para a qualificação de gestores escolares. Com efeito, surge o Programa de Capacitação a Distância para Gestores Escolares (Progestão). Esse Programa foi implementado em 2001 pelo Conselho Nacional de Secretários de Educação (Consed) e ofertou formação continuada aos gestores escolares em serviço da rede pública por meio das modalidades presencial e a distância (BARREIRO; MOURA, 2010; GATTI, 2008). O Progestão visava a uma gestão democrática e mais participativa, voltado para a promoção da autonomia escolar e do intercâmbio com a comunidade escolar, uma vez que se entendia que era preciso, nos moldes da recém-aprovada LDB, consolidar mecanismos e procedimentos de participação e gestão colegiada na escola; destacar a relação entre a construção do projeto pedagógico e o exercício da autonomia na escola; e analisar mecanismos de envolvimento de 
alunos, pais, professores e funcionários em ações compartilhadas na tomada de decisões e na gestão da escola (DOURADO; DUARTE, 2001, p. 68).

No último ano do mandato presidencial de FHC, o Governo do Estado de Minas Gerais implementou o Projeto Veredas, que vigorou entre 2002 e 2005. Os docentes-alvo do Projeto foram os que lecionavam nos anos iniciais do ensino fundamental. $\bigcirc$ Projeto elegeu a EaD como estratégia de formação e pretendia ofertar uma habilitação em nível superior aos professores que não tinham a formação inicial exigida para exercerem o magistério nas áreas em que atuavam (MAGALHÃES, 2005).

Apesar dos avanços, o Governo de Fernando Henrique impôs um severo retrocesso na educação superior em razão da reestruturação desse sistema, notadamente marcado pela expansão privada de matrículas, na esteira do processo de expansão do capital. As universidades públicas foram as que mais amargaram com o modelo liberal instaurado. As reformas educacionais propostas, no âmbito das universidades, pretendiam impulsionar a

[...] expansão de matrículas, a criação de cursos noturnos, ao mesmo tempo em que proibia concursos para contratação de docentes, congelava salários, já reduzidos a índices aviltantes, estimulou aposentadorias precoces, forçou a ampliação da carga didática em detrimento da pesquisa - uma das consequências da GED. ${ }^{6}$ (SHIROMA; MORAES; EVANGELISTA, 2004, p. 96).

A era FHC terminou em dezembro de 2002, com muitos apontamentos negativos na área da Educação como o não cumprimento da criação de um programa nacional para aperfeiçoar a formação dos docentes que atuavam nas creches; o MEC deu pouco apoio a programas de formação de professores em Educação Especial, não aumentou o repasse de verbas para Estados e Municípios para o desenvolvimento de programas de alfabetização voltados à Educação de Jovens e Adultos (EJA), principalmente em nível federal, ocorreu

6 Gratificação de Estímulo à Docência (GED), um componente que foi adicionado à remuneração básica do professor da carreira de magistério superior. 
o fechamento de universidades, instalou-se uma lógica de mercado/comércio do ensino e não definiu e nem implementou a autonomia universitária plena.

Fernando Henrique também conseguiu cumprir algumas metas de governo como a definição de diretrizes curriculares nacionais para creches e pré-escolas e lançou programas como o Fundef e o Toda Criança na Escola, que contribuíram para aumentar os indicadores quantitativos do ensino fundamental. A eleição de Luís Inácio Lula da Silva em janeiro de 2003 mudou o paradigma estatal em relação às políticas sociais e educacionais, apesar da manutenção da política econômica (PAULANI, 2006). Lula, eleito presidente pelo Partido dos Trabalhadores (PT), permaneceu no poder por dois mandatos sucessivos, de janeiro de 2003 a janeiro de 2011 . O Governo de Luiz Inácio foi marcado por uma expansão dos investimentos nas áreas da Educação e da Assistência Social, com substanciais avanços nos indicadores sociais.

\section{A POLÍTICA DE FORMAÇÃO INICIAL E CONTINUADA DE PROFESSORES EM GOUERNOS DE CENTRO-ESQUERDA: A AGENDA EDUCACIONAL NOS GOUERNOS LULA E DILMA}

\subsection{O GOUERNO LULA (2003-2010)}

Em 20 de outubro de 2003, Lula apresenta uma reforma do Ensino Superior por meio de um decreto que cria o Grupo de Trabalho Interministerial (GTI), grupo designado para analisar a conjuntura da educação superior no País. O GTI também deveria propor um plano de ação que atendesse a alguns aspectos centrais, como a reestruturação, o desenvolvimento e a democratização das Instituições Federais de Ensino Superior (IFES) uma vez que a pressão por mais e boas escolas gerou um aumento significativo no número de estudantes nos diversos graus de ensino, propiciando, por sua vez, condições de mais e melhor pressão pela democratização dos níveis mais altos, atingindo e forçando as "portas" da universidade, historicamente fechadas aos setores populacionais 
de menor poder aquisitivo. Cresciam as reivindicações por universidades mais acessíveis à população (MICHELOTTO, 1999, p. 21).

$\bigcirc$ Grupo de Trabalho Interministerial, ao apresentar seu relatório final, assinala que "a última década foi de desarticulação do setor público brasileiro; as universidades federais não foram poupadas. Como em todo o setor público, o quadro geral das universidades brasileiras é de crise." (BRASIL, 2003).

De um lado, as universidades governamentais sofreram consequências da crise fiscal do Estado que incidem sobre seus recursos humanos, de manutenção e de investimento. De outro lado, a prioridade ao setor privado em todas as áreas também chegou ao setor do ensino superior: as universidades privadas, que viveram uma expansão recorde nos últimos anos, chegando a responder, em 2002 , por $63,5 \%$ do total de cursos de graduação e $70 \%$ das matrículas, encontram-se agora ameaçadas pelo risco de uma inadimplência generalizada do alunado e de uma crescente desconfiança em relação a seus diplomas. Essas duas faces de uma mesma realidade demandam soluções estruturais, possíveis somente se houver: (i) um programa emergencial de apoio ao ensino superior, especialmente às universidades federais e (ii) uma reforma universitária mais profunda. (BRASIL, 2003).

Segundo o GTI, os problemas das IFES seriam resolvidos se algumas estratégias fossem adotadas: destinar mais recursos a essas instituições; reforçar a autonomia universitária; fazer com que o governo federal se comprometesse com a reposição do quadro docente; eleger a EaD como um dos pilares para a formação de professores por meio da rede de IFES; ampliar a oferta de vagas para estudantes e definir instrumentos de controle que buscam a avaliação das IES, bem como dos cursos de graduação e da performance dos estudantes.

Em relação a esse último ponto, em 2004, é publicada a Lei n. 10.861, que estabelece o Sistema Nacional de Avaliação da Educação Superior (Sinaes). Esse documento prevê:

Art. $1^{\circ}$ Fica instituído o Sistema Nacional de Avaliação da Educação Superior - SINAES, com o objetivo de assegurar processo nacional de avaliação das instituições de educação superior, dos cursos de graduação e do 
desempenho acadêmico de seus estudantes, nos termos do art. 9. VI, VIII e IX, da Lei no 9.394, de 20 de dezembro de 1996. (BRASIL, 2004).

Ainda em 2003, o MEC criou a Rede Nacional de Formação Continuada de Professores, de incumbência das Secretarias de Educação a Distância e de Educação Básica do MEC, em parceria com os IFES, os Estados e os Municípios. A Rede Nacional de Formação Continuada de Professores visava institucionalizar a assistência das demandas por formação continuada. O enfoque dessa Rede era a Educação Infantil e o Ensino Fundamental (GATTI; BARRETO; ANDRÉ, 201 l).

Em poucos anos de atuação do Governo Lula o ensino superior já começava a demonstrar sinais de reestruturação educacional. Durante todo o ano 2004, o Ministério da Educação promoveu debates com a comunidade acadêmica e a sociedade para mobilizar a elaboração de um desenho novo de universidade, que fosse mais coerente com as necessidades do País, que estava em expansão e que necessitava de um sistema de educação superior comprometido com a qualidade e que pudesse responder pela formação inicial e continuada dos professores em nível nacional, em larga escala. Dessa maneira, o sistema de ensino público deveria ser democrático e também alcançar um número maior de pessoas em todas as partes do País. Com esses imperativos, em 2005, o MEC publica o Decreto n. 5.622/2005, ${ }^{7}$ que regulamentou a Educação a Distância (EaD) no Brasil.

Para compreendermos melhor a concepção de Educação a Distância no Brasil, é necessário ter como referência o Decreto n. 5.622, de 19 de dezembro de 2005, que assentiu a EaD, em seu artigo $1^{\circ}$, como modalidade de ensino "[...] na qual a mediação didático-pedagógica nos processos de ensino e aprendizagem ocorre com a utilização de meios e tecnologias de informação e comunicação, com estudantes e professores desenvolvendo atividades educativas em lugares ou tempos diversos." (BRASIL, 2005). Assim, alargase a "[...] procura por cursos de formação inicial e continuada de professores oferecidos na modalidade a distância, por instituições públicas e privadas. A

7 O Decreto n. 5.622, de 19 de dezembro de 2005, foi revogado pelo Decreto n. 9.057, de 2017. 
Universidade Aberta do Brasil (UAB) surge nesse contexto" (ORTH et al., 2013, p. 45) como um sistema interligado por várias instituições de ensino superior públicas, que passam a oferecer cursos direcionados à população que tem dificuldade de acesso à formação superior.

Dessa maneira, a UAB tornou-se um dos principais instrumentos de execução das políticas de formação em nível superior do MEC, ao lado do Programa de Apoio aos Planos de Reestruturação e Expansão das Universidades Federais (Reuni) (GATTI; BARRETO; ANDRÉ, 2011, p. 63). Com efeito, a propagação dessa modalidade de ensino foi basilar para a implementação de vários projetos educacionais e para as mais diversas conjunturas, como: estudos formais em todos os níveis (MAIA; MATTAR, 2007), campanhas de alfabetização, cursos profissionalizantes, capacitação para o trabalho, assim como outros campos do sistema educacional (LITWIN, 2001).

Em 2007, a Lei Federal n. 11.502 alterou o escopo de atuação da Coordenação de Aperfeiçoamento de Pessoal de Nível Superior (Capes), que, desde sua fundação em 1951, regulava o ensino superior (BRASIL, 2007). Segundo Geglio (2015, p. 234), com a nova Lei, essa agência também passou a possuir a tarefa de implementar e operacionalizar políticas públicas de formação inicial e formação continuada voltada para os professores da Educação Básica, com recursos que advinham do Fundo Nacional de Desenvolvimento da Educação (FNDE).

Em 2009 é lançado o Plano de Formação do Professor (Parfor). Com essa ação, as funções da Rede Nacional de Formação Continuada de Professores foram redefinidas e ganharam maior alcance. A Rede passa a ser nomeada Rede Nacional de Formação Continuada de Profissionais da Educação Básica. Assim, a Rede passa a abranger um número maior de projetos de formação por intermédio da operacionalização via IES. Dentre seus objetivos, destacase agenciar um "conjunto de ações estratégicas de formação continuada, articuladas entre si com o objetivo de contribuir para a melhoria da formação de professores e alunos da educação básica." (GATTI; BARRETO; ANDRÉ, 201 l, p. 56). Os programas estratégicos que integraram essa Rede foram, entre outros: Pró-Letramento, Gestar II e Especialização em Educação Infantil. 
Em 2005, o Programa Pró-Letramento foi implementado e possuía como público-alvo os professores dos anos iniciais. Esse Programa era executado pelo MEC em parceria com as universidades e com a adesão dos estados e dos municípios. O Pró-Letramento tinha a finalidade de salvaguardar a melhoria da qualidade da aprendizagem dos conteúdos de escrita, de leitura e de matemática. O Programa incentivava os professores a empregarem o uso de abordagens mais adequadas à faixa etária dos anos iniciais:

Pró-Letramento é um curso semipresencial de 120 horas, divididas em 84 horas presenciais e 36 a distância, com duração de oito meses em cada uma das etapas: aprendizagem da leitura/escrita, aprendizagem da matemática. O material, impresso e em vídeo, é de autoria coletiva de dez universidades e composto por oito fascículos de alfabetização e linguagem e oito de matemática. Ele é distribuído a professores cursistas e tutores, e estes recebem também DVDs que complementam os cursos. (GATTI; BARRETO; ANDRÉ, 201 l, p. 56).

A implantação do Pró-Letramento teve seu início oficial em 2006, em cinco estados da região Nordeste: Rio Grande do Norte, Ceará, Maranhão, Piauí e Bahia. Até 2007, duração da primeira fase do Programa, cerca de 40.000 professores haviam concluído o curso. Nos anos posteriores, outros estados foram agrupados ao Programa, como Amazonas, Amapá, Mato Grosso, Paraíba, Rio de Janeiro e Roraima.

Em 2004, o Programa Gestar II substituiu o Gestar I, instituído em 2001, cujo público-alvo era os docentes das séries iniciais. Dessa maneira, - Programa Gestar II foi concebido para oferecer a formação continuada em língua portuguesa e em matemática aos professores dos anos finais do ensino fundamental. $\bigcirc$ Programa Gestar II tinha como finalidade: contribuir para a melhoria do processo ensino-aprendizagem dos estudantes nas áreas de língua portuguesa e matemática; colaborar para o aperfeiçoamento das práticas pedagógicas e da autonomia do professor; e estimular o professor ao desenvolvimento de um trabalho fundamentado em competências e habilidades. O Programa Gestar II era constituído por dois cursos: Curso de Formação de Professores para cada uma das áreas e Curso de Formação de Professores 
Formadores/Tutores. $\bigcirc$ Programa modificou sua estrutura e sua abrangência no ano 2008. De tal modo, o Gestar II passou a ser implementado em parceria entre o MEC e as IES.

Ainda em 2004, o MEC fundiu duas secretarias para criar a Secretaria de Educação Continuada, Alfabetização e Diversidade (SECADI), que possuía como eixo norteador a diversidade e, posteriormente, passou a englobar a inclusão social. Dentro dessa Secretaria foram desenvolvidos os seguintes Programas: Programa Identidade Étnica e Cultural dos Povos Indígenas (2004), que financiava projetos de educação indígena, bem como material pedagógico e formação professores; Programa de Formação Superior e Licenciaturas Indígenas (2005), apoiando projetos de IES públicas vinculadas às comunidades indígenas voltados para a formação superior e a permanência de docentes indígenas na graduação; Programa de Ações Afirmativas para a População Negra (2005), cujo foco era a ampliação e o acesso das pessoas negras ao ensino superior; Programa Educação para a Diversidade e Cidadania (2005), que visava à qualificação de profissionais da Educação para a temática de orientação sexual e de identidade de gênero; e Projeto Educando para a Igualdade Gênero, Raça e Orientação Sexual (2005-2006), que destinava a formação de professores para os temas de gênero, orientação sexual e diversidade étnico-racial.

Em 2010, é lançado o curso presencial de especialização em Educação Infantil, com carga horária de 360 horas, destinado ao atendimento aos docentes, coordenadores e diretores que atuavam na Educação Infantil em creches e pré-escolas. $\bigcirc$ curso objetivava favorecer a ampliação dos conhecimentos sobre as concepções das crianças de 0 a 3 e de 4 a 5 anos de idade. Foram ofertadas 3.400 vagas, que se distribuíram entre os 17 estados que firmaram parcerias com o MEC.

Dentre as várias ações de formação em distintas frentes de atuação, a gestão das escolas também é valorizada. Assim, em 2009, o Programa Escola de Gestores da Educação Básica é criado. Implementado em diversos estados e operacionalizado por uma rede de universidades, o Programa ofereceu, em nível de pós-graduação lato sensu, os seguintes cursos: Especialização em Coordenação Pedagógica (carga horária de 405 horas), Especialização em 
Gestão Escolar (carga horária de 400 horas) e Aperfeiçoamento em Gestão Escolar (carga horária de 200 horas).

Durante o Governo Lula ocorreram outras políticas públicas, como o Programa Expandir e o Reuni. O Programa Expandir, em 2006, promoveu a criação de 10 Instituições de Ensino Superior e a expansão de 48 campi. Em 2007, o Programa surge sob a nomenclatura de Reestruturação e Expansão das Universidades Federais (Reuni). Com a sucessão presidencial, a Presidente Dilma assume o governo e reafirma a continuidade dos programas de criação e expansão da educação superior iniciados no Governo Lula.

\subsection{O GOUERNO DILMA (2011-2016)}

Em 2011, o Presidente Lula é sucedido por Dilma Vana Rousseff, também pertencente ao PT. A Presidente Dilma governou o Brasil no período de 2011 a 2014, ano em que foi reeleita, garantindo o direito ao segundo mandato, que se iniciou em primeiro de janeiro de 2015. Em agosto de 2016, Dilma sofre um processo de impeachment, passando a presidência do Brasil ao seu vice, Michel Temer.

Dilma Rousseff, em decorrência do pertencimento ao mesmo partido do presidente anterior, dá continuidade à agenda implementada pelo Presidente Lula, "investindo em políticas e em programas que visavam à manutenção dos resultados obtidos desde 2003." (WALDOW, 2014, p. 3). No campo educacional, seu governo assumiu a postura de que a qualidade da educação passa pela formação continuada e pela remuneração digna do professor (STANGUERLIN, 2014, p. 14). Em seu primeiro mandato, a Presidente Dilma cria o Programa de Governo Para o Brasil seguir mudando, no qual são expostos 13 compromissos, entre eles o sétimo referindo-se à educação.

No que diz respeito à educação, o primeiro mandato do Governo Dilma foi marcado pela expansão do ensino público brasileiro desde a préescola até a pós-graduação. Nesse sentido, foram feitos investimentos que previam a construção de seis mil creches e pré-escolas e 10 mil quadras 
esportivas cobertas, estabelecendo, dessa forma, uma articulação entre as políticas públicas educacionais, de esporte e cultura. No que se refere ao ensino superior, houve um crescimento significativo de matrículas nas universidades federais e nas instituições privadas por meio do Reuni e do Prouni, ${ }^{8}$ a continuação da construção dos Institutos Federais que oferecem cursos técnicos de nível médio e subsequente, além da criação do Pronatec. ${ }^{9}$ De acordo com Ferreira (2012, p. 468):

A política para a educação superior do governo Dilma vem enfatizando os seguintes parâmetros a serem incorporados pelas universidades: inovação, empreendedorismo, competitividade, formação e atração de capital humano, mobilidade internacional, universidade como agente de desenvolvimento econômico e social, foco em áreas estratégicas/prioritárias de estudo e de pesquisa, internacionalização da educação superior.

No campo da formação de professores, houve um aumento na oferta de cursos e de ações voltadas para essa finalidade. Em 2012, em conjunto com as Secretarias de Educação Estaduais e Municiais, foi implementado o Plano Nacional de Alfabetização na Idade Certa (PNAIC), que possuía como objetivos: garantir que todos os estudantes dos sistemas públicos de ensino estivessem alfabetizados, em língua portuguesa e em matemática, até o final do $3^{\circ}$ ano do ensino fundamental, melhorar o Índice de Desenvolvimento da Educação Básica (IDEB), entre outros. O PNAIC possuía como eixos: materiais didáticos, literatura e tecnologias educacionais; avaliação e gestão, controle e mobilização social. $\bigcirc$ principal eixo do Programa era a formação continuada do professor alfabetizador, com projeção de formar até 2015 cerca de 360 mil docentes. Nesse sentido, Stanguerlin (2014, p. 14-15) destaca que:

\footnotetext{
8 O Programa Universidade para Todos (Prouni) foi criado pelo Governo Federal em 2004 e oferece bolsas de estudos integrais (100\%) e parciais (50\%) em instituições particulares de educação superior, em cursos de graduação e sequenciais de formação específica, a estudantes brasileiros sem diploma de nível superior.

9 Programa Nacional de Acesso ao Ensino Técnico e Emprego (Pronatec) foi criado pelo Governo federal em 2011 com o objetivo de expandir, interiorizar e democratizar a oferta de cursos de educação profissional e tecnológica no País.
} 
[...] a formação inicial e continuada do professor tem sido um dos pilares das últimas políticas educacionais e atuação do professor é considerada pelos governos como pontuais na busca da educação de qualidade. Então se considera importante destacar que o Pacto Nacional pela Alfabetização na Idade Certa representa mais uma via do governo no que tange a formação do professor para melhorar os resultados apresentados que são medidos através dos instrumentos oficiais de avaliação.

Em 2013 emergiram várias manifestações que marcaram o rompimento entre o campo político e a participação social. Essa ação, segundo Avritzer (2016), evidenciou conflitos entre os movimentos sociais e o Partido dos Trabalhadores (PT). As manifestações ocorreram em várias partes do País. Inicialmente, foram voltadas para a melhoria dos serviços públicos prestados e se redimensionaram, nos anos seguintes, para a crítica ao Governo da Presidente Dilma e ao Partido dos Trabalhadores. Os manifestantes, oriundos da classe média e de grupos escolarizados, apontavam Dilma Rousseff e o PT como os responsáveis pela corrupção no País. Essa ação aproximou diversos partidos políticos de oposição.

Dilma Rousseff, no segundo turno nas eleições de 2014, foi reeleita com uma margem de votos reduzida. Nesse contexto, a Presidente começou a enfrentar um Congresso Nacional muito mais hostil e composto, em sua maioria, por bases conservadoras. $\bigcirc$ principal partido político da base aliada, o PMDB, mostrava-se com reservas, principalmente com a eleição de Eduardo Cunha para a presidência da Câmara dos Deputados no ano 2015, situação que somente agravou os entraves políticos para a Presidente Dilma. Segundo Avritzer (2016), a origem desse entrave advém de uma natureza estrutural, situação essa que impediu a ampliação de uma agenda mais progressista no Brasil.

Para o seu segundo mandato, a Presidente Dilma apresentou o plano de governo intitulado Mais Mudanças, Mais Futuro, em que ela faz um apanhado dos últimos 12 anos dos impactos políticos no Brasil, ressaltando os avanços em todos os sentidos. Nesse plano, Dilma busca sanar os problemas estruturais que impedem o pleno desenvolvimento do País de forma a garantir que não ocorram retrocessos nas conquistas obtidas na última década. Para 
tanto, seu plano de governo se atrela a dois pilares, sendo eles: a solidez econômica e a amplitude das políticas sociais.

Para a formação continuada de professores não há muitas mudanças, preservando as ações do primeiro mandato, que, em grande medida, davam continuidade àquelas implementadas no Governo Lula, como "[...] a ampliação do financiamento via Fundo de Manutenção e Desenvolvimento da Educação Básica e de Valorização dos Profissionais da Educação (FUNDEB), o Piso do Magistério, as Conferências e os Fóruns de Educação, o PNE 2014-2024 [...]" (EDITORIAL, 2016, p. 333).

Em 2015, o MEC, por meio da Secretaria de Educação Básica (SEB) publicou um edital para o credenciamento de Instituições Públicas Federais de Ensino Superior, de modo que pudessem manifestar interesse em participar do Programa Nacional de Certificação de Diretores Escolares, programa que substituiria o Programa Nacional Escola de Gestores. As Instituições Públicas Federais de Ensino Superior contempladas deveriam coordenar e executar o processo de formação continuada dos diretores escolares da Educação Básica Pública. Essa certificação ocorreria mediante cursos em níveis de aperfeiçoamento ( 180 a 200 horas) e de atualização (100 a 120 horas), ambos ofertados na modalidade a distância.

Após ser reeleita como presidente em 2005, Dilma Rousseff afirma em sua posse que sua gestão seria com base no lema Brasil, Pátria Educadora (FRANÇA; ALMEIDA; SILVA, 2016). Esse discurso de Dilma marcava com sinais que a educação seria uma prioridade em seu novo governo. Durante os nove meses em que permaneceu como presidente, já desgastada pela crise política, Dilma enfrentou diversos problemas relacionados à pasta da Educação. Nesse curto espaço de tempo, ocorreram três trocas de ministros: Cid Gomes (02/01/2015 a 19/03/2015), Renato Janine Ribeiro (06/04/2015 a 04/10/2015) e Aloizio Mercadante (05/10/2015 a 1 1/05/2016). Menos de seis meses depois da reeleição de Dilma Rousseff, o Ministério do Planejamento anunciou um corte bilionário no orçamento da educação, fruto das políticas de contingenciamento orçamentário e de ajuste fiscal que foram impostas em virtude da crise econômica que se abateu sobre o País desde 2010. Assim, 
A constituição e a trajetória histórica das políticas educacionais no Brasil, em especial os processos de organização e gestão da educação básica nacional, tem sido marcada hegemonicamente pela lógica da descontinuidade, por carência de planejamento de longo prazo que evidenciasse políticas de Estado em detrimento de políticas conjunturais de governo. (DOURADO, 2007, p. 925).

O ajuste fiscal produziu diversos efeitos perversos, em várias áreas. No caso do MEC, diversas ações de formação de professores foram descontinuadas ou tiveram uma sensível redução nos recursos a elas destinados. Houve, portanto, claro retrocesso, nada condizente com o mote de campanha e slogan do Governo Brasil, Pátria Educadora.

Em agosto de 2016, a Presidente Dilma Rousseff é afastada da presidência do País. Esse afastamento ocorreu em razão das circunstâncias apresentadas em um conturbado processo de crime de responsabilidade fiscal, que culminou com seu impeachment. Com a retirada de Dilma, seu vice-presidente, Michel Temer, assumiu definitivamente a presidência em 31 de agosto de 2016.

\section{O RETROCESSO E A GUINADA À DIREITA-LIBERAL: O GOUERNO TEMER (2016-2018)}

Em agosto de 2016, foi aprovado na Câmara dos Deputados o processo de impeachment da Presidenta Dilma Rousseff. Desse modo, acentuou-se a crise econômica que começou a se desenvolver na segunda metade do seu primeiro mandato, sendo agravada no início do segundo, justificando a política de austeridade fiscal que passa a vigorar a partir de então.

No mesmo ano, Eduardo Cunha (PMDB-RJ) foi afastado do mandato de deputado federal e, de modo consequente, do cargo de presidente da Câmara dos Deputados. De tal modo, Michel Temer, passou a comandar uma coalizão política 
nova no Brasil com a ativa participação do partido político PSDB (AVRITZER, 2016). Assim, a presidência do País foi assumida pelo vice-presidente, Michel Temer, pertencente ao Partido do Movimento Democrático Brasileiro (PMDB), partido que cria um plano de governo liberal intitulado Uma ponte para o futuro. Com a mudança no governo, a agenda liberal é retomada e aprofundada.

Michel Temer propõe inúmeras mudanças radicais para o País, dentre elas destacam-se o aumento do tempo de contribuição para a Previdência Social a fim de se alcançar a aposentadoria com salário integral e as novas configurações para o sistema educacional brasileiro. Ambas as mudanças impactam significativamente nas políticas de formação inicial e continuada de professores da educação básica, em razão dos significativos cortes financeiros previstos e concluídos e até o momento. Nesse contexto profundamente marcado pela descontinuidade das políticas públicas educacionais, cabe recuperar o alerta de Lombardi e Saviani (2008) quando trataram do primado da agenda política em detrimento da agenda do Estado, afirmando que a alternância e a descontinuidade das políticas educacionais voltadas para a formação inicial e continuada de professores impedia a superação dos problemas no campo educacional uma vez que a visão de curto prazo sempre prevalecia, moldada pelos ciclos político-eleitorais:

[...] parece que cada governo, cada secretário de educação ou cada ministro quer imprimir sua própria marca, deixando de lado os programas implementados nas gestões anteriores. Com esse grau de descontinuidade não há como fazer frente às questões especificamente educacionais dado que, como se mostrou, trata-se de um tipo de atividade que requer continuidade. (LOMBARDI; SAVIANI, 2008, p. 271).

Por meio da Proposta de Emenda da Constituição n. 241, a PEC n. 241, renomeada pelo Senado Federal com o n. 55/2016, que institui o Novo Regime Fiscal no Brasil para os próximos 20 anos (2016-2036), o Governo Temer propôs e efetivou inúmeros cortes orçamentários, podendo ser alterado no décimo ano (AMARAL, 2016). Segundo esse autor: 
Novo Regime Fiscal (NRF), válido para a União, significa, na prática, "congelar", nos valores de 2016, as despesas primárias do Poder Executivo, do Poder Judiciário, do Poder Legislativo, do Tribunal de Contas da União (TCU), do Ministério Público Federal (MPF) e da Defensoria Pública da União (DPU) pelo longo prazo de 20 anos, uma vez que os valores somente poderão sofrer reajustes até os percentuais referentes à inflação do ano anterior, medida pelo Índice Nacional de Preços ao Consumidor Amplo (IPCA), divulgado pelo Instituto Brasileiro de Geografia e Estatística (IBGE). (AMARAL, 2016, p. 654).

$\bigcirc$ período que abrange o Novo Regime Fiscal interfere diretamente no Plano Nacional de Educação (PNE) aprovado pela Lei n. 13.005, de 25 de junho de 2014, além de, também, envolver-se no próximo período do PNE previsto para 2025-2035. Assim, as metas para o desenvolvimento da educação brasileira ficarão imersas em meio aos cancelamentos de vários programas e projetos de caráter social para a formação inicial e continuada de professores oferecidos nas Instituições de Ensino Superior. No que se refere aos cortes financeiros, o grupo editorial da Revista Educação e Sociedade afirma que:

A limitação de gastos impedirá o cumprimento das metas estabelecidas no Plano Nacional de Educação (PNE), entre elas e, sobretudo, a efetivação da educação obrigatória para todos os jovens entre quatro e 17 anos, o estabelecimento do CAQ/CAQI (Custo aluno qualidade/Custo aluno qualidade inicial) e a valorização do magistério da educação básica como política obrigatória em todo o território nacional. Caso aprovada e implementada essa PEC, veremos retroceder o acesso às escolas e universidades públicas, como correspondente incrementando de sua privatização. (EDITORIAL, 2016, p. 330).

Além da questão exposta, a PEC n. 241 interfere indiretamente em outros pontos da agenda educacional. Vejamos, por exemplo, a LDB, no que se refere à formação específica para o exercício docente. Na gestão Temer, sem considerar a opinião pública, ocorre a autorização de profissionais de outras áreas para atuarem como docentes, pelo conceito do "notório saber", isto é, não é obrigatório que o professor que atuará na rede de educação pública ou privada tenha cursado uma licenciatura, basta demonstrar os conhecimentos 
necessários. Essa ação vai de encontro ao PNE, que estabelece a necessidade de se garantir que todos os professores da educação básica possuam graduação na área em que atuam. $\bigcirc$ Governo de Michel Temer em vez de tentar corrigir a distorção da falta de docentes, com a ampliação de licenciaturas, agrava mais o problema com essa medida, considerando que a PEC n. 241 congela os investimentos por 20 anos, inclusive na área da Educação.

Governo extinguiu várias secretarias do Ministério da Educação e fundiu o Ministério da Educação com o Ministério da Cultura, invalidando, dessa forma, uma conquista dos movimentos populares de cultura, de artistas e de intelectuais. Em razão da grande resistência de várias partes as secretarias são novamente separadas, e o Ministério da Cultura é novamente criado. Nesse processo, o Presidente decide não abrir novas adesões em 2016 para programas importantes de ampliação e melhoria da Educação, como o Mais Educação, colocando também em xeque o Pronatec, o PNAIC, o Parfor, o Ciências sem Fronteiras ${ }^{10}$ e o Ensino Médio Inovador. As ações de formação de professores sob a responsabilidade da Secretaria de Educação Básica (SEB) e da SECADI também são interrompidas, com a suspensão de novas ofertas. Somente as ações em andamento foram mantidas. $\bigcirc$ Governo divulgou, também, a suspensão do Programa Nacional e Certificação de Diretores Escolares.

Nesse sentido, podemos considerar que o atual Governo brasileiro retrocede em muitos aspectos, pois elimina direitos anteriormente conquistados, principalmente no que diz respeito à formação de professores, e, em decorrência disso, os programas de formação continuada passam a não fazer sentido, sendo, dessa forma, suspensos e/ou extintos. Assim, claro está que a formação inicial e continuada de docentes não é, definitivamente, uma das prioridades do Governo Temer.

10 O Programa Ciências sem Fronteira foi extinto no ano 2017. 


\section{CONSIDERAÇÕES FINAIS}

Neste artigo descreveu-se e analisou-se o campo da formação a partir de uma perspectiva político-institucional, voltada para a definição de políticas educacionais em nível estratégico, no âmbito do MEC e do Governo federal, ao longo dos últimos 25 anos. É nesse nível que as políticas são forjadas e desenhadas, refletindo a agenda governamental e os interesses predominantes.

As políticas educacionais são direta e largamente afetadas pela agenda governamental. Em um país como o Brasil, marcado pelo "presidencialismo de coalizão", modelo em que o Presidente da República é impelido a construir um amplo espectro de alianças em nome da governabilidade, tal agenda corre sério risco de ser capturada e/ou contingenciada, tornando-se refém do partido - e do ministro - que estiver à frente da pasta.

Da mesma forma, o federalismo brasileiro, caracterizado pela descentralização administrativa e pela desconcentração orçamentária, confere aos estados e municípios relativa autonomia decisória, potencializando distintos desenhos de políticas e programas em nível local. Para o caso da educação e da formação de professores, essas duas questões explicam sobremaneira como o percurso nesse campo tem sido tortuoso, tenso, contraditório e, mais recentemente, marcado por retrocessos.

Quais são os desdobramentos dessa análise? Se as ações são definidas naquele nível, há que se compreender onde se efetivam. As ressonâncias ocorreram em nível local, que operacionaliza e dá materialidade às diretrizes definidas estrategicamente. Isso significa que as escolas, as salas de aula e os professores são os últimos elos dessa cadeia extensa, responsável pela implementação e pela tradução do que a eles é comunicado pelas autoridades educacionais, seja em nível municipal, estadual, seja federal.

Claro está que o Brasil vem sofrendo grandes oscilações políticas que têm afetado todas as áreas da atuação governamental, incluindo, obviamente, o campo educacional. $\bigcirc$ ajuste promovido por Dilma e agravado por Temer é prova inequívoca de que o País adere ao primado do orçamento, quando a questão fiscal predomina sobre a finalidade e os objetivos de cada área. 
No caso da educação, os cortes impostos ao MEC fizeram com que a política nacional de formação inicial e continuada de professores fosse interrompida e, consequentemente, desarticulada. Em outras palavras, a suspensão das ações de formação financiadas pelo Ministério em parceria com as universidades públicas, responsáveis pela sua implementação e operacionalização, produziu um efeito devastador em nível local. Porque as secretarias de educação dos pequenos e médios municípios são as que mais dependem dos programas federais para capacitarem seus professores e os profissionais que atuam nas escolas públicas. A descontinuidade da política nacional de formação docente é um grave desincentivo à profissão, contribuindo ainda mais para a precarização e fragilização do trabalho desses profissionais.

Da mesma forma, o Governo federal parece desconhecer o efeito cascata que tais medidas produzem nas equipes responsáveis pela formação dos professores. Se, em grande medida, as ações são coordenadas local e regionalmente pelas universidades, a constituição de equipes e a definição de desenhos formativos, itinerários pedagógicos e estratégias didáticas requer tempo, planejamento e contínua sistematização dos processos e das experiências. A interrupção das ações desarticulou completamente as equipes locais, que, desfeitas, perderam a expertise acumulada ao longo dos anos em que estiveram envolvidas diretamente com os cursistas.

Percebe-se, na trajetória das políticas de formação de professores descritas ao longo desses últimos 25 anos no Brasil, como ciclos políticos eleitorais foram decisivos para assegurar avanços e permitir que as demandas do campo fossem contempladas. Entretanto, os mesmos ciclos políticos eleitorais contribuíram para os retrocessos que, infelizmente, têm predominado nos anos recentes, produzindo uma grave esquizofrenia entre essas duas pontas: a que define, estrategicamente, e a que implementa, localmente. 


\section{REFERÊNCIAS}

AMARAL, N. C. PEC 241/55: a "morte" do PNE (2014-2024) o poder de diminuição dos recursos educacionais. Revista Brasileira de Política e Administração da Educação, v. 32, n. 3, p. 653-673, set./dez. 2016. Disponível em: <https://goo.gl/eZok55>. Acesso em: 17 dez. 2017.

AVRITZER, L. Impasses da democracia no Brasil. Rio de Janeiro: Civilização Brasileiras, 2016.

BARREIRO, I. M. de F.; MOURA, G. G. Gestão democrática na escola: as impressões dos participantes do programa Progestão. Revista Eletrônica de Educação, p. 11 1-125, 2010. Disponível em: <https://goo.gl/VdsL9v>. Acesso em: 17 dez. 2017.

BRASIL. Constituição. República Federativa do Brasil de 1988. Brasília, DF: Senado Federal, 1988. Disponível em: <https://goo.gl/Wm2CPQ>. Acesso em: 11 jun. 2017.

BRASIL. Decreto n. 5.622, de 19 de dezembro de 2005. Diário Oficial da União, Brasília, DF, 19 dez. 2005. Disponível em: <https://goo.gl/X5eMDi>. Acesso em: 04 jun. 2017.

\section{BRASIL. Diretrizes Nacionais do Programa Escola de Gestores da Educa- ção Básica Pública. Brasília, DF: MEC/SEB, 2009.}

BRASIL. Lei n. 9.394, de 20 de dezembro de 1996. Estabelece as diretrizes e bases da educação nacional. Diário Oficial da União, Brasília, DF, 23 dez. 1996. Disponível em: <https://goo.gl/FvyuRX>. Acesso em: 04 jun. 2017.

BRASIL. Lei n. 10.861, de 14 de abril de 2004. Institui o Sistema Nacional de Avaliação da Educação Superior - SINAES e dá outras providências. Diário Oficial da União, Brasília, DF, 14 abr. 2004. Disponível em: <https://goo.gl/ KsJ3DV>. Acesso em: 04 jun. 2017.

BRASIL. Lei n. 1 1.502, de 11 de julho de 2007. Modifica as competências e a estrutura organizacional da fundação Coordenação de Aperfeiçoamento de Pessoal de Nível Superior - CAPES, de que trata a Lei no 8.405, de 9 de janeiro de 1992; e altera as Leis nos 8.405, de 9 de janeiro de 1992, e 11.273 , de 6 de fevereiro de 2006, que autoriza a concessão de bolsas de estudo e de pesquisa a participantes de programas de formação inicial e continuada de professores para a educação básica. Diário Oficial União, Brasília, DF, 12 jul. 2007. 
BRASIL. Portaria n. 867, de 04 de julho de 2012. Institui o Pacto Nacional pela Alfabetização na Idade Certa e as ações do Pacto e define suas diretrizes gerais. Brasília, DF, 2012. Disponível em: <https://goo.gl/sbnU6c>. Acesso em: 01 jan. 2018.

BRASIL. Presidência da República. Grupo de trabalho interministerial. Bases para o enfrentamento da crise emergencial das universidades brasileiras e roteiro para a reforma da universidade brasileira. Brasília, DF, 2003. Disponível em: <https://goo.gl/RPo7mH>. Acesso em: 04 jun. 2017.

CATANI, A. M.; OLIVEIRA, J. F de. A educação superior. A organização do ensino no Brasil: níveis e modalidades na Constituição federal e na LDB. São Paulo: Xamã, 2002. Disponível em: <https://goo.gl/FQPiBG> Acesso em: 12 mar. 2017.

CROSSO, C.; AZZI, D.; BOCK, R. Banco Mundial em Foco: um ensaio sobre sua atuação na educação brasileira e na América Latina. São Paulo: Ação Educativa, 2007.

CUNHA, L. A. Zigue-zague no Ministério da Educação: uma visão da educação superior. Revista Contemporânea de Educação, v. l, n. l, 2006.

CUNHA, M. A. A. Guia Geral do Proformação. Brasília, DF: MEC/FUNDESCOLA, 2000.

DOURADO, L. F; DUARTE, M. R. T. Progestão: como promover, articular e envolver a ação das pessoas no processo de gestão escolar. Módulo II. Brasília, DF: Conselho Nacional de Secretários de Educação, 2001.

DOURADO, L. F. Políticas e gestão da educação básica no Brasil: limites e perspectivas. Educação \& Sociedade, Campinas, v. 28, n. 100, p. 921-946, out. 2007. Edição especial. Disponível em: <http://www.cedes.unicamp.br>. Acesso em: 02 mar. 2017.

EDITORIAL. O contexto político e a educação nacional. Educação \& Sociedade, Campinas, v. 37, n. 135, p. 329-334, abr./jun. 2016. Disponível em: $<$ https://goo.gl/yTNjlq >. Acesso em: 11 jun. 2017.

FERREIRA, S. Reformas na educação superior: de FHC a Dilma Rousseff (1995-2011). Linhas Críticas, v. 18, n. 36, 2012. 
FRANÇA, M. L. C.; ALMEIDA, G. M.; SILVA, I. C. O. Greve (in)felizmente: reflexões sobre o declínio do professor numa pátria educadora. Encontro Internacional de Formação de Professores e Fórum Permanente de Inovação Educacional, v. 9, n. 1, 2016.

GATTI, B. A. Análise das políticas públicas para formação continuada no Brasil, na última década. Revista Brasileira de Educação, v. 13, n. 37, jan./abr. 2008. Disponível em: <https://goo.gl/cJs9Kl>. Acesso em: 11 abr. 2016.

GATTI, B. A.; BARRETO, E. S. de S.; ANDRÉ, M. E. D. de A. Políticas docentes no Brasil: um estado da arte. Brasília, DF: Unesco, 2011.

GEGLIO, P. C. Políticas públicas de formação continuada para professores: um estudo de cursos realizados a partir de propostas licitatórias. Revista Ensaio: Avaliação e Políticas Públicas em Educação, v. 23, n. 86, p. 23l-257, 2015.

HYPOLITO, Á. M. Reorganização gerencialista da escola e trabalho docente. Educação: Teoria e Prática, v. 21, n. 38, p. 59-78, 2011.

LITWIN, E. Educação a Distância: temas para o debate de uma nova agenda educativa. Porto Alegre: Artmed, 2001.

LOMBARDI, J. C.; SAVIANI, D. (Org.). Marxismo e educação: debates contemporâneos. 2. ed. Campinas: Autores Associados, 2008.

MAGALHÃES, J. M. de P. Projeto veredas, desenvolvimento profissional e exercício da docência: ouvindo professoras cursistas e seu tutor. 2012. Dissertação (Mestrado em Educação)-Pontifícia Universidade Católica de Minas Gerais, Belo Horizonte, 2005. Disponível em: <https://goo.gl/3WNClN>. Acesso em: 04 jun. 2017.

MAIA, C.; J. MATTAR. ABC da EaD: a Educação a Distância hoje. 1. ed. São Paulo: Pearson, 2007.

MICHELOTTO, R. M. A liberação do acesso e a extensão como estratégias de democratização da universidade: a experiência da Itália e do Brasil. 1999. Tese (Doutorado em Educação)-Universidade Federal de São Carlos, São Carlos, 1999.

NÓVOA, A. Concepções e práticas de formação contínua de professores. In: Universidade de Aveiro. Formação contínua de professores: realidades e perspectivas. Aveiro: Ed. Universidades de Aveiro, 1991. 
ORTH, M. A et al. Ambientes virtuais de aprendizagem e formação continuada de professores na modalidade a distância//Virtual learning environments and continuous teachers training in distance modality. Conjectura: filosofia e educação, v. 18, n. 1, p. 42-58, 2013.

PAULANI, L. M. Capitalismo financeiro e estado de emergência econômica no Brasil: o abandono da perspectiva do desenvolvimento. In: JORNADA DE ECONOMIA CRÍTICA, 10., 2006, Barcelona. Anais... Barcelona, 2006. Disponível em: <encurtador.com.br/bsxM8>. Acesso em: 31 jan. 2018.

SAVIANI, D. A nova lei da educação: trajetória, limites e perspectivas. Campinas: Autores Associados, 1997.

SCHÖN, D. A. La formación de profissionales reflexivos. Barcelona: Paidós, 1992.

SCHÖN, D. A. Formar professores como profissionais reflexivos. In: NÓVOA, A. (Org.). Os professores e sua formação. Lisboa: Dom Quixote, 1995.

SHIROMA, E. O.; MORAES, M. C. M. de; EVANGELISTA, O. Política educacional. DP\&A Editora, 2004.

SILVA JÚNIOR, J. dos R. A reforma da educação superior dos anos 90: a produção da ciência engajada ao mercado e à produção de um novo pacto social. Sorocaba: Universidade de Sorocaba; São Paulo: PUC/SP, 2002.

SOARES, M. C. C. Banco Mundial: políticas e reformas. In: TOMMASI, L.; WARDE, M. J.; HADDAD, S. (Org.). O Banco Mundial e as políticas educacionais. São Paulo: Cortez, 2003.

STANGUERLIN, T. M. G. Pacto nacional pela alfabetização na idade certa - algumas considerações. Curitiba, 2014. Disponível em: < https://goo.gl/ qTSK6h>. Acesso em: 11 jun. 2017.

UNESCO. Declaração Mundial sobre Educação para Todos: satisfação das necessidades básicas de aprendizagem. Jomtien: Unesco, 1990.

UNESCO. Educação para todos: o compromisso de Dakar. Brasília, DF: Ação Educativa, 2001.

WALDOW, C. As políticas educacionais do governo Dilma, a formação para o trabalho e a questão do Pronatec: reflexões iniciais. In: ANPED SUL, 10., 2014, Florianópolis. Anais... Florianópolis, 2014. Disponível em: <https:// goo.gl/a8zB8a>. Acesso em: 11 jun. 2017. 
ZEICHNER, K. M. Para além da divisão entre professor-pesquisador e pesquisador acadêmico. In: GERALDI, C. M. G.; FIORENTINI, D.; PEREIRA, E. M. de A. (Org.). Cartografias do trabalho docente: professor(a) pesquisador(a). Campinas: Mercado das Letras, 1998.

Recebido em 02 de fevereiro de 2018 Aceito em 03 de abril de 2018

Endereços para correspondência: Universidade Federal de Ouro Preto, Centro de Educação Aberta e a Distância, Campus Universitário Morro do Cruzeiro, 35400-000, Ouro Preto, Minas Gerais, Brasil; breynner.oliveira@gmail. com 